\title{
Typical and Atypical Imaging Findings of Hepatocellular Carcinoma on Multiphasic MDCT Scan in Histologically Proved Cases
}

\author{
Umakant Prasad ${ }^{1}$ Deepak Kumar ${ }^{1}$ Rashmi Rani Bharti ${ }^{2}$ Sanjay Kumar Suman ${ }^{1}$ Aishwerya Singh ${ }^{1}$ \\ Ravikant Kumar ${ }^{3}$
}

1 Department of Radiodiagnosis, Indira Gandhi Institute of Medical

Address for correspondence Deepak Kumar, MD, Department of Science, Patna, Bihar, India

2 Department of Pathology, Indira Gandhi Institute of Medical Science, Patna, Bihar

${ }^{3}$ Department of Gastroentrology, Indira Gandhi Institute of Medical Radiodiagnosis, Room No: 251, Indira Gandhi Institute of Medica Science, Patna 800014, Bihar, India

Science, Patna, India

J Gastrointestinal Abdominal Radiol ISGAR 2022;5:135-139.

\begin{abstract}
Keywords

- HCC

- Cystic changes

- Multiphasic MDCT scan

- Intratumoral pseudoaneurysm

Objective The purpose of this study was to find out the incidence of typical and atypical radiological imaging findings of hepatocellular carcinoma (HCC) on multiphase multidetector computed tomography (MDCT) scans in histologically proven cases.

Materials and Methods A multiphase computed tomography study of 73 patients with histologically proven $\mathrm{HCC}$ was evaluated by a radiologist. Our multiphasic protocol was composed of precontrast, arterial, portal, and delayed venous phases. The reviewers analyzed the CT images for tumor size, enhancement patterns of HCC in different phases, relative timing of washout, internal cystic changes, and presence of dysmorphic intratumoral vessel aneurysms or arteriovenous shunt.

Results Most of the cases (95.9\%) showed typical enhancement patterns in MDCT, i.e., enhancements in the arterial phase with the portal or delayed venous phase contrast washout. Three cases $(4.9 \%)$ out of $73 \mathrm{HCC}$ showed enhancements in the portal phase and washout in the delayed venous phase. Seven cases out of total $73 \mathrm{HCC}$ (9.5\%) patients showed heterogeneous enhancements in both arterial and portal phases and contrast washout in the delayed venous phase. Venous thrombosis was noted in about 44 cases (60\%) out of total 73 patients, in which portal vein thrombosis was more common than hepatic veins/inferior vena cava.

Conclusion Most of the HCC show typical enhancement patterns, i.e., heterogeneous enhancements in the arterial phase and washout in the portal venous phase when we use MDCT. These findings are higher than those described previously. However, in our study, the main difference with MDCT was lower frequency of intratumoral pseudoaneurysm and bile duct invasion, and intratumoral fat and calcification (atypical character of HCC) were not found which were rare findings in previous study.
\end{abstract}

published online

February 18, 2022
DOI https://doi.org/

$10.1055 / \mathrm{s}-0042-1742771$. ISSN 2581-9933. (c) 2022. Indian Society of Gastrointestinal and Abdominal Radiology. All rights reserved.

This is an open access article published by Thieme under the terms of the Creative Commons Attribution-NonDerivative-NonCommercial-License, permitting copying and reproduction so long as the original work is given appropriate credit. Contents may not be used for commercial purposes, or adapted, remixed, transformed or built upon. (https://creativecommons.org/ licenses/by-nc-nd/4.0/)

Thieme Medical and Scientific Publishers Pvt. Ltd., A-12, 2nd Floor, Sector 2, Noida-201301 UP, India 


\section{Introduction}

Hepatocellular carcinoma (HCC), one of the leading causes of cancer-related death, is the fifth most common tumor worldwide, and its incidence continues to rise. ${ }^{1-5}$ Approximately, 70 to $90 \%$ of HCCs are developed on the background of established liver cirrhosis or advanced fibrosis. ${ }^{2}$ Hepatitis B virus and/or hepatitis $\mathrm{C}$ virus infection, alcohol, and nonalcoholic fatty liver disease are the most predominant risk factors for HCC worldwide. ${ }^{3}$ Early detection of HCC is very important because several curative treatment options are available. Ultrasonography is the choice for the screening of HCC in high-risk patients. Multiphasic contrast-enhanced computed tomography (CT) scan is the standard diagnostic test for HCC. The arterial phase enhancement of hepatic nodules with subsequent contrast washout in the portal or delayed venous phase is considered to be the definitive imaging feature of HCC and recommended in the guidelines by various associations for liver studies ${ }^{6-8}$

\section{Materials and Methods}

\section{Patients}

This retrospective study was approved by the ethics committee board of our institute. In this study, from October 2019 to October 2020, 73 patients of histologically proven HCC were considered who underwent multidetector computed tomography (MDCT) using a dedicated triple-phase liver protocol before receiving any treatment. All pregnant women with HCC, all patients hypersensitive to CT contrast agents, and in-patients in whom CT is contraindicated due to any other reason were excluded in this study.

\section{CT Technique}

All patients were scanned by multislice (128 slice) Toshiba CT scan (Aquilion) and underwent multi-phase MDCT including noncontrast, arterial, portal, and venous phases. The following CT parameters were used: $5 \mathrm{~mm}$ collimation, 0.5 to $2.5 \mathrm{~mm}$ slice thickness, $2.5 \mathrm{~mm}$ reconstruction interval, table speed of $13.5 \mathrm{~mm}$ per rotation, 150 to $250 \mathrm{~mA}$ effective current, $120 \mathrm{kVp}$ tube potential, and $512 \times 512$ matrix size. First of all, non-contrast CT abdomen images were obtained and then triple-phase CT images were obtained after the injection of $120 \mathrm{~mL}$ nonionic contrast (Iohexol 300) at the rate of 3 to $4 \mathrm{~mL} / \mathrm{sec}$ by an automatic power injector and arterial phase imaging was obtained 20 seconds after the achievement of $100 \mathrm{HU}$ attenuation in descending aorta by the bolus tracker method. Portal phase imaging was performed 40 seconds after the arterial phase, and delayed venous phase was obtained 180 seconds after the contrast administration with the standard reconstruction algorithm and sent to picture archiving and communication system.

\section{CT Image Analysis}

Images were analyzed retrospectively by an experienced abdominal radiologist, and enhancement patterns (in arterial or portal phase), contrast washout (in portal or delayed venous phase), internal cystic degeneration, internal abnormal vessel, and portal vein/hepatic vein status were evaluated.
Table 1 Triple-phase CT findings

\begin{tabular}{|l|l|l|}
\hline Triple-phase CT finding & $\begin{array}{l}\text { Number } \\
(\boldsymbol{n})\end{array}$ & $\begin{array}{l}\text { Percentage } \\
(\%)\end{array}$ \\
\hline Arterial phase enhancement & 70 & 95.9 \\
\hline Portal phase enhancement & 3 & 4.1 \\
\hline $\begin{array}{l}\text { Arterial and portal } \\
\text { phase enhancement }\end{array}$ & 7 & 9.5 \\
\hline $\begin{array}{l}\text { Portal phase washout } \\
\text { Delayed venous washout }\end{array}$ & 7 & 90.5 \\
\hline $\begin{array}{l}\text { Internal cystic degeneration } \\
\text { within HCC }\end{array}$ & 15 & 20.5 \\
\hline $\begin{array}{l}\text { Internal tumor aneurysm } \\
\text { Hepatic artery hepatic } \\
\text { venous shunt } \\
\text { Hepatic artery portal shunt }\end{array}$ & 2 & 2.7 \\
\hline Portal vein thrombosis & 29 & 4.1 \\
\hline Hepatic vein thrombosis & 6 & 39 \\
\hline IVC thrombosis & 9 & 8 \\
\hline Liver mets & 17 & 12 \\
\hline Distant mets & 11 & 23 \\
\hline
\end{tabular}

Abbreviations: CT, computed tomography; HCC, hepatocellular carcinoma; IVC, inferior vena cava.

Statistical analysis was performed using SPSS software, and frequency and percentage were used as descriptive statistics for categorical and ordinal variables.

\section{Results}

All 73 patients of HCC (biopsy proved) underwent multiphase (unenhanced, arterial, portal, and venous phase) MDCT imaging, and typical and atypical enhancement patterns of HCC and its morphology were assessed by the radiologist ( $\mathbf{- T a b l e ~} \mathbf{1}$ ). The size of the HCC lesions ranged from 3 to $17 \mathrm{~cm}$ (mean, $10 \mathrm{~cm}$ ), and most were infiltrative rather than well defined. In most of the cases, HCC was single and in about 17 cases (23\%), HCC was multifocal. Seventy (95.9\%) cases showed typical enhancement patterns in MDCT, i.e., enhancements in the arterial phase with the portal or delayed venous phase contrast washout. Heterogeneous enhancements in the arterial phase were noted in the most of the cases except few small multifocal HCC $(<1 \mathrm{~cm})$ which showed homogenous enhancements. Three cases (4.9\%) out of 73 HCC showed enhancements in the portal phase and washout in the delayed venous phase. Seven cases out of total 73 HCC (9.5\%) patients showed heterogeneous enhancements in both arterial and portal phases and contrast washout in the delayed venous phase.

Internal cystic degeneration was found in approximately 15 (20.5\%) cases. Venous thrombosis was noted in about 44 cases $(60 \%)$ out of total 73 patients, in which portal vein thrombosis was more common than hepatic veins/inferior vena cava (IVC). Portal vein thrombosis was noted in 29 cases out of total $44(65 \%)$ and hepatic vein thrombosis in six cases (13\%) and IVC thrombosis in nine cases. In few cases, thrombosis reached up to the right atrium. 
Table 2 Vascular finding in triple-phase CT

\begin{tabular}{|l|l|l|}
\hline Vascular changes & Number $(\boldsymbol{n})$ & Percentage (\%) \\
\hline Venous thrombosis & 44 & $60(n=44 / 73)$ \\
\hline Portal vein thrombosis & 29 & $65(n=29 / 44)$ \\
\hline Hepatic vein thrombosis & 6 & $13(n=6 / 44)$ \\
\hline IVC thrombosis & 9 & $20(n=9 / 44)$ \\
\hline $\begin{array}{l}\text { Hepatic arteriovenous } \\
\text { shunt }\end{array}$ & 32 & $43.8(n=32 / 73)$ \\
\hline $\begin{array}{l}\text { Hepatic arterioportal } \\
\text { shunt }\end{array}$ & 29 & $91(n=29 / 32)$ \\
\hline $\begin{array}{l}\text { Hepatic arterior hepatic } \\
\text { veinous shunt }\end{array}$ & 3 & $9(n=3 / 32)$ \\
\hline $\begin{array}{l}\text { Intratumoral } \\
\text { pseudoaneurysm }\end{array}$ & 2 & $2.7(n=2 / 73)$ \\
\hline
\end{tabular}

Abbreviations: CT, computed tomography; IVC, inferior vena cava.

Table 3 Age and sex distribution of the study population

\begin{tabular}{|l|l|l|}
\hline Parameter & Number & Percentage (\%) \\
\hline Age (years) & & \\
\hline $30-50$ & 13 & 17.8 \\
\hline$>50$ & 60 & 82.2 \\
\hline Sex & & \\
\hline Male & 57 & 78 \\
\hline Female & 16 & 22 \\
\hline
\end{tabular}

Table 4 Causative factor of HCC

\begin{tabular}{|l|l|l|}
\hline Parameters & Number & Percentage (\%) \\
\hline Causative factor & & \\
\hline Hepatitis B & 34 & 46.6 \\
\hline Hepatitis C & 5 & 6.8 \\
\hline Alcoholic & 4 & 5.5 \\
\hline Others & 30 & 41.1 \\
\hline
\end{tabular}

Abbreviation: HCC, hepatocellular carcinoma.
Forty three percent cases $(n=32)$ showed arteriovenous shunt in which about $39 \%$ cases $(n=29)$ showed hepatic arterioportal shunt (HAPS) and three cases (4.1\%) showed hepatic artery hepatic vein shunt (HAHVS). Intratumoral pseudoaneurysm (ITPA) was found in only $2.7 \%$ cases $(n=2)$ (-Table 2).

Males (78\%) were more affected in comparison to females (22\%) and most of the patients were above the fifth decade (82.2\%) (-Table 3).

Hepatitis B was the most common cause of HCC (46.6\%), other causative agents were alcohol, hepatitis $C$, hepatitis $A$, and others (-Table 4 ).

\section{Discussion}

HCC is the fifth most common cancer in the world and is the third most common cause of cancer-related death (after lung and stomach cancer). HCC has a distinctive pattern of enhancements on MDCT as a result of the predominantly hepatic arterial supply of HCC. Lee et al showed that 137 out of 243 cases (56.4\%) of HCC (biopsy proved) showed typical enhancement patterns, i.e., arterial phase enhancements with portal or equilibrium phase washout, and $43.6 \%$ cases showed atypical enhancements, i.e., iso-hypoattenuation in the arterial phase or no washout until the delayed venous phase. In our study, typical enhancements were noted in approximately $95.9 \%$ cases $(n=70 / 73)$ which is higher than those described in the previous study (-Fig. 1) and approximately $4.1 \%$ cases showed enhancements in the portal phase and $9.5 \%$ cases showed enhancements in both arterial and portal phase $(n=7 / 73)$ and delayed venous phase washout in our study.

The cystic degeneration within HCC is extremely rare, there being few cases in the literature, and ${ }^{9-11}$ in our study, about $20 \%$ cases $(n=15)$ showed the internal cystic area in HCC. Cystic degeneration is mainly due to internal necrosis in large tumors ( - Fig. 2). Cystic degeneration in HCC is also seen after treatment in few cases (35). Cystic degeneration/necrosis within HCC after loco-regional chemo-embolization is associated with lower rates of recurrence. ${ }^{12,13}$

Vascular invasion, the entrance of tumor cells into the lumen of vessels, is a characteristic feature of progressed HCC. ${ }^{14}$ Such invasion distinguishes HCC from secondary liver cancers, which rarely invade intrahepatic vessels. ${ }^{15}$ Portal veins are invaded more commonly than hepatic veins;

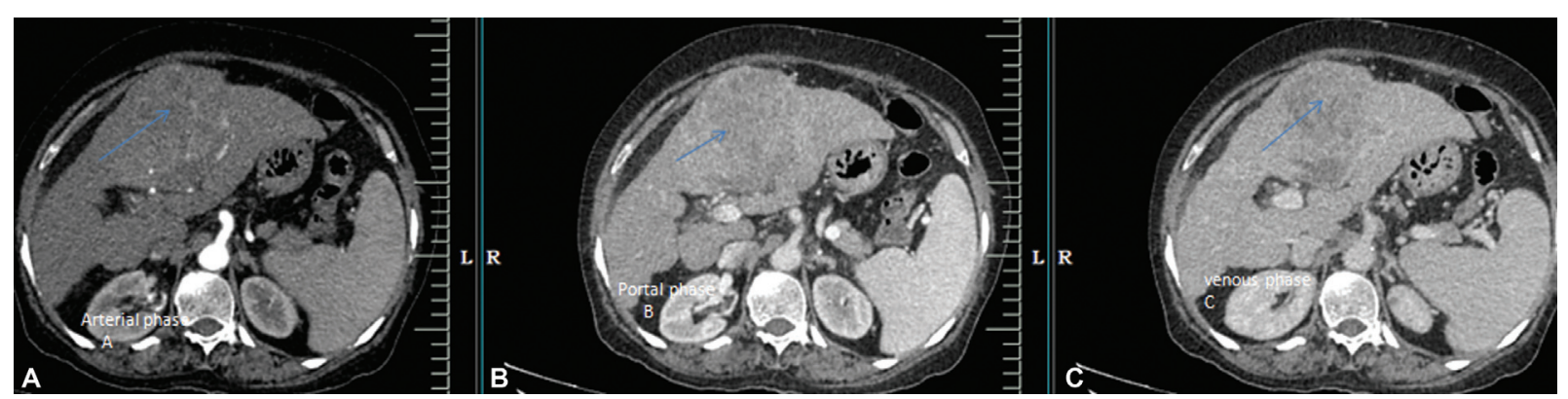

Fig. 1 Triple phase computed tomography scan show enhancements of tumor in (A) the arterial phase and (B) washout in portal and (C) delayed venous phase. 


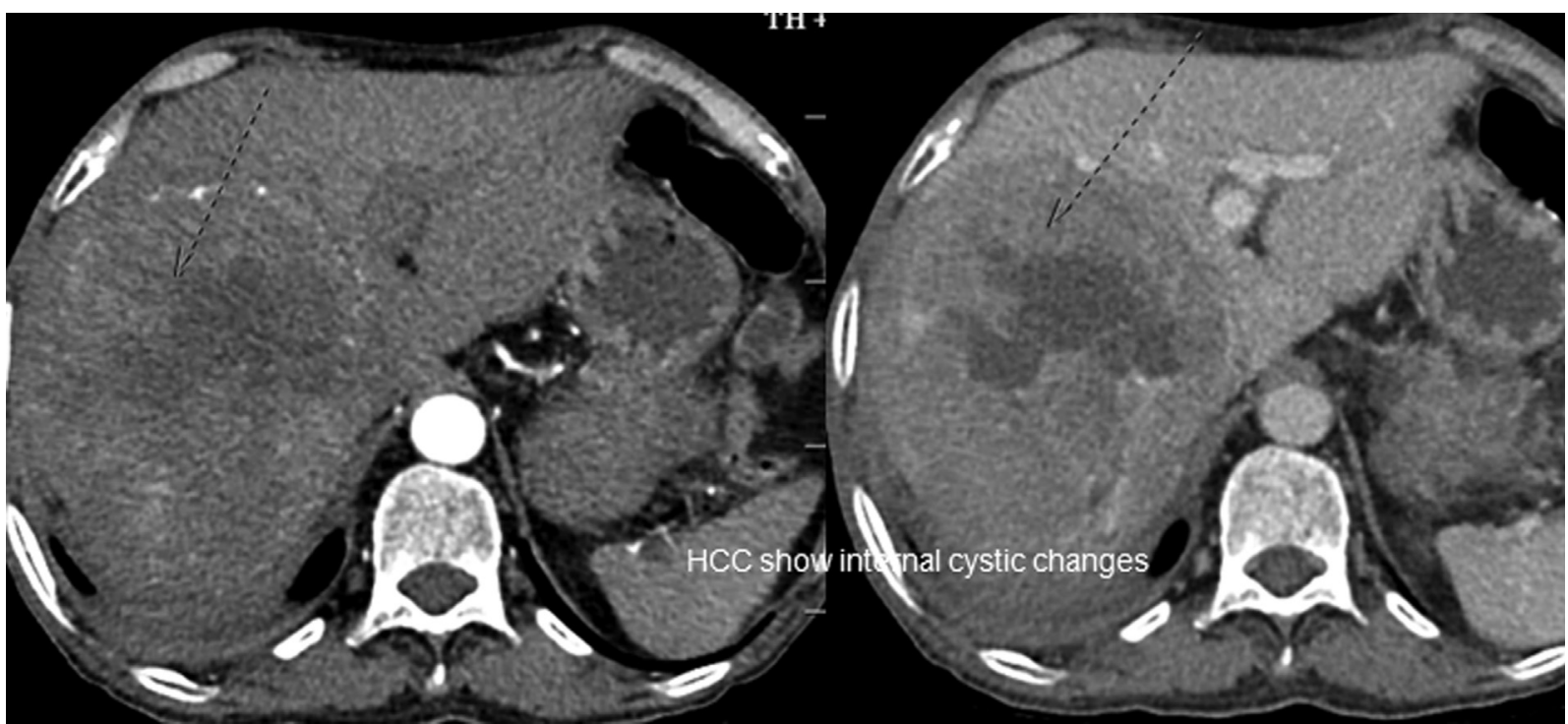

Fig. 2 Computed tomography image of hepatocellular carcinoma (HCC) showing internal cystic necrosis, more visualized in the delayed venous phase.

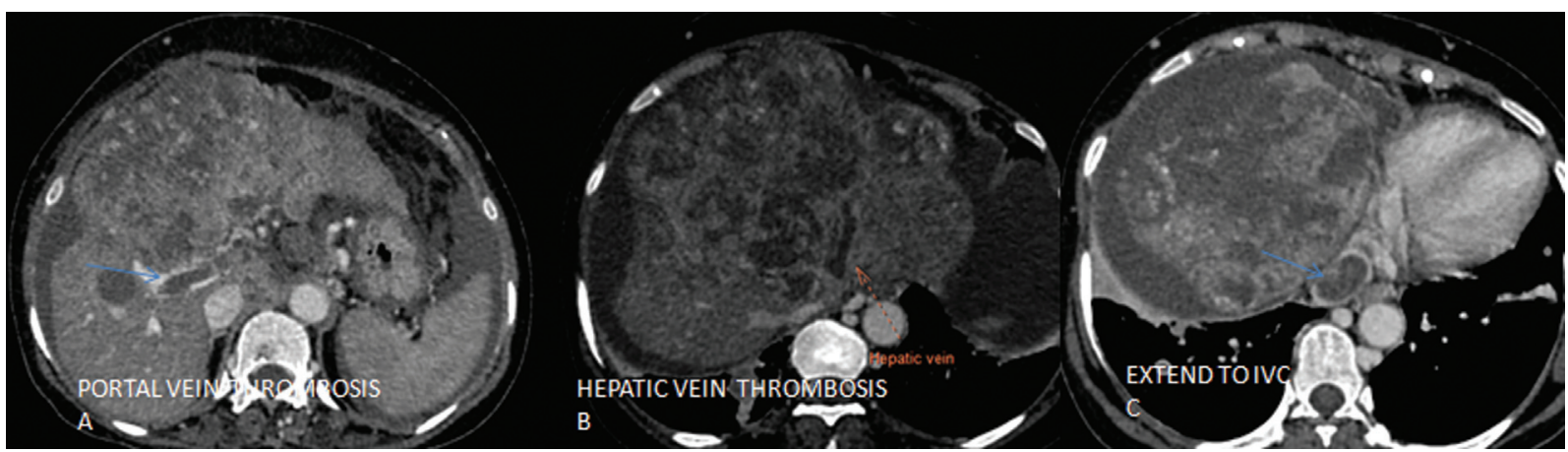

Fig. 3 (A-C) Triple-phase computed tomography scan of hepatocellular carcinoma showing tumoral thrombosis of portal vein and hepatic vein which extends up to intrahepatic inferior vena cava (IVC).

hepatic arteries are not invaded. ${ }^{14}$ In our study, about $39 \%$ cases $(n=29)$ showed portal vein involvement and $8 \%$ cases $(n=6)$ showed hepatic vein involvement and nine cases showed IVC thrombosis, in which thrombus reaches up to the right atrium in few cases. It is very important to differentiate bland thrombus from neoplastic involvement of vessels (neoplastic thrombus enhances in the arterial phase similar to HCC) (- Fig. 3).

Bile duct invasion is very rare clinically in HCC, but it was found in 5 to $10 \%$ cases of autopsy series. ${ }^{16,17} \mathrm{CT}$ may show soft tissue enhancing mass in the bile duct with ductal dilatation proximal to obstruction. In this study, no cases showed bile duct invasion.

Ngan et al demonstrate that approximately $31.2 \%$ cases of HCC showed hepatic arteriovenous shunt (HAVS), shunting into portal vein was observed in approximately $28.8 \%$ and shunting into hepatic vein in approximately $2.4 \%$. In our study, approximately $39 \%$ cases $(n=29)$ showed HAPS and $5 \%$ cases $(n=3)$ showed HAHVS which are slight higher frequency than those in previous study. HCC is the most common hepatic tumor associated with HAVS, because of its

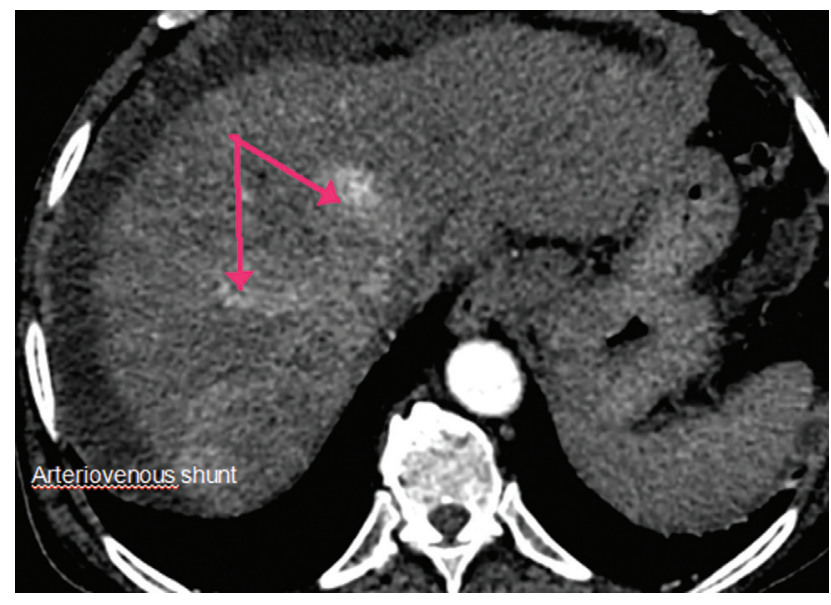

Fig. 4 Arterial phase computed tomography image of hepatocellular carcinoma showing arteriovenous shunt.

easy invasion into the portal vein or hepatic vein or their branches (-Fig. 4).

ITPA in HCC without prior intervention is very rare finding. In previous study, about $5 \%$ cases of HCC showed ITPA without any prior intervention. ${ }^{18}$ In our study, only $2.7 \%(n=2)$ cases 


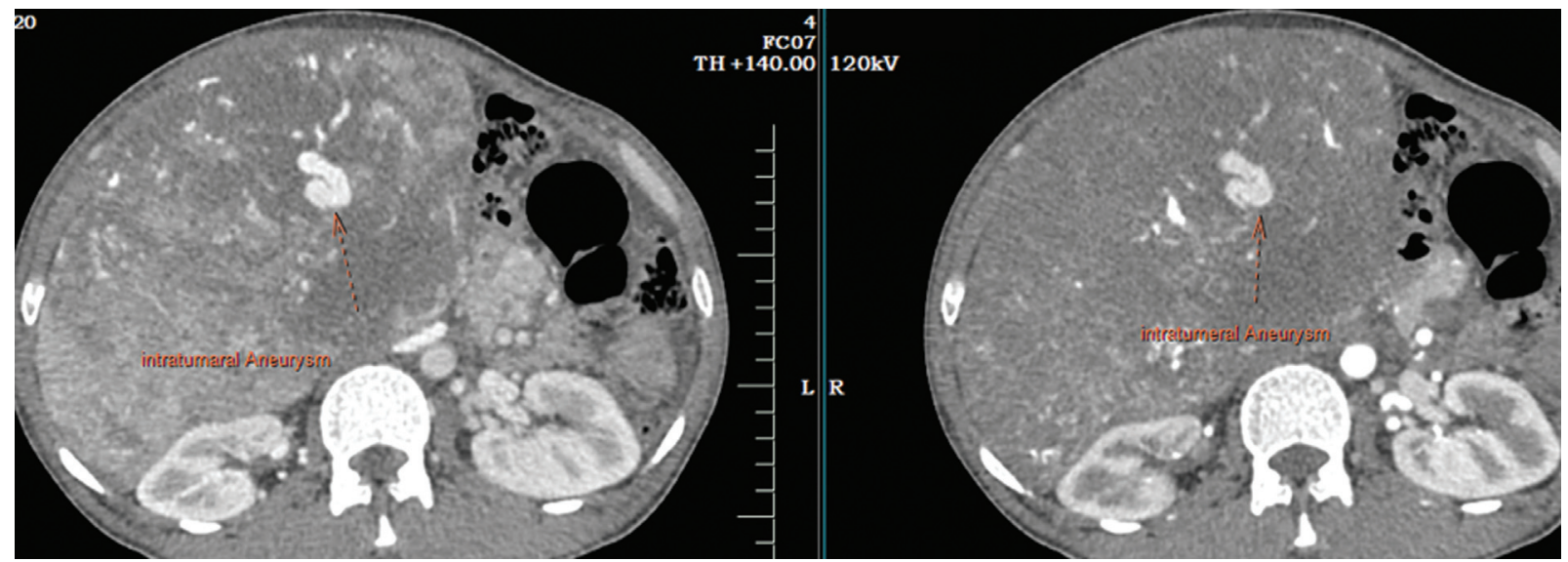

Fig. 5 Arterial phase computed tomography image of hepatocellular carcinoma showing intratumoral pseudoaneurysm.

showed ITPA which is slight lower than those of previous study, may be due to mild small sample size (-Fig. 5).

In conclusion, most of the HCC show typical enhancement patterns in multiphasic scans, i.e., heterogeneous enhancements in the arterial phase and washout in the portal venous phase. These findings are higher than those described previously. However, in our study, the main difference with MDCT was lower frequency of ITPA and bile duct invasion, and fat and calcification (atypical character of HCC) within tumor were not found which were rare findings in the previous study.

\section{Funding \\ None.}

\section{Conflict of Interest}

None declared.

\section{Acknowledgments}

The authors would like to thank patients, their families, and the Department of Radiodiagnosis of the institute.

\section{Reference}

1 Bruix J, Sherman M, Llovet JM, et al; EASL Panel of Experts on HCC European Association for the Study of the Liver. Clinical management of hepatocellular carcinoma. Conclusions of the Barcelona2000 EASL conference. J Hepatol 2001;35(03):421-430

2 Forner A, Llovet JM, Bruix J. Hepatocellular carcinoma. Lancet 2012;379(9822):1245-1255

3 Dimitroulis D, Damaskos C, Valsami S, et al. From diagnosis to treatment of hepatocellular carcinoma: an epidemic problem for both developed and developing world. World J Gastroenterol 2017;23(29):5282-5294

4 Parkin DM, Bray F, Ferlay J, Pisani P. Estimating the world cancer burden: Globocan 2000. Int J Cancer 2001;94(02):153-156

5 Velázquez RF, Rodríguez $M$, Navascués $C A$, et al. Prospective analysis of risk factors for hepatocellular carcinoma in patients with liver cirrhosis. Hepatology 2003;37(03):520-527
6 Omata M, Lesmana LA, Tateishi R, et al. Asian Pacific Association for the study of the liver consensus recommendations on hepatocellular carcinoma. Hepatol Int 2010;4(02):439-474

7 Bruix J, Sherman MPractice Guidelines Committee, American Association for the Study of Liver Diseases. Management of hepatocellular carcinoma. Hepatology 2005;42(05):1208-1236

8 Forner A, Vilana R, Ayuso C, et al. Diagnosis of hepatic nodules $20 \mathrm{~mm}$ or smaller in cirrhosis: prospective validation of the noninvasive diagnostic criteria for hepatocellular carcinoma. Hepatology 2008;47(01):97-104

9 Nagano K, Fukuda Y, Nakano I, et al. An autopsy case of multilocular cystic hepatocellular carcinoma without liver cirrhosis. Hepatogastroenterology 2000;47(35):1419-1421

10 Gonwa ME, Casillas J, Livingstone AS, Robinson PG. Cystic hepatocellular carcinoma: CT findings. J Comput Assist Tomogr 1991; 15(06):1045-1047

11 Pombo F, Rodriguez E, Arnal-Monreal F. Multicystic fibrolamellar hepatocellular carcinoma. CT appearance. Clin Imaging 1993;17 (01):67-69

12 Sotiropoulos GC, Malago M, Molmenti EP, et al. Disease course after liver transplantation for hepatocellular carcinoma in patients with complete tumor necrosis in liver explants after performance of bridging treatments. Eur J Med Res 2005;10(12): 539-542

13 Majno PE, Adam R, Bismuth $\mathrm{H}$, et al. Influence of preoperative transarterial lipiodol chemoembolization on resection and transplantation for hepatocellular carcinoma in patients with cirrhosis. Ann Surg 1997;226(06):688-701

14 Edmondson HA, Steiner PE. Primary carcinoma of the liver: a study of 100 cases among 48,900 necropsies. Cancer 1954;7(03): 462-503

15 Okuda K. Hepatocellular carcinoma: clinicopathological aspects. J Gastroenterol Hepatol 1997;12(9-10):S314-S318

16 Theise ND, Curado MP, Franceschi S, et al. Hepatocellular carcinoma. In: Bosman FT, Carneiro F, Hruban RH, Theise ND, eds. WHO Classification of Tumours of the Digestive System. 4th ed. Lyon, France: IARC; 2010:205-216

17 Kojiro M. Histopathology of liver cancers. Best Pract Res Clin Gastroenterol 2005;19(01):39-62

18 Haider Z, Idris M, Sajjad Z, Humayun S, Kashif N, Ali S. Intratumoral pseudoaneurysms in hepatocellular carcinoma: do they occur de novo without any prior intervention? A tertiary care center experience of 6 years. Acta Radiol 2015;56(09):1027-1033 